\title{
MOVING FROM VALUE SENSITIVE DESIGN To Virtuous Practice Design
}

\section{Introduction}

In recent decades, a burgeoning literature on methods for practising ethics in research and innovation (R\&I) settings has emerged (Reijers et al., 2017). These methods aim at anticipating the ethical impacts of emerging technologies, evaluating the ethical impacts of existing technologies, and/or enabling, ensuring and organising what we might call ethical technology design. One of the most prominent approaches in this field, especially with regard to ethical technology design, is the value sensitive design (VSD) approach, which was developed by Batya Friedman in the 1990s. It initially focused on computer science and information systems research (Friedman, 1996; Friedman and Kahn, 2002). Later on, the approach was adopted to practise VSD for myriad applications of R\&I, such as care robots (Van Wynsberghe, 2013), urban simulation planning (Borning et al., 2004), shale gas exploitation (Dignum et al., 2016) and Nano-medicine (Timmermans et al., 2011). The great merit of VSD is that it offers a way for ethics and sociological studies concerned with normative issues to enter practical settings in which R\&I activities take place. In other words, it offers an "integrated" approach to ethics in design (Cummings, 2006, p.713). However, VSD should not be considered a complete design methodology but an approach that can integrate ethical concerns in existing design practices (Timmermans et al., 2011, p. 280).

In this paper, we criticise the reliance of VSD on a heuristic of values and offer an alternative to this heuristic, called 'virtuous practice design' (VPD), by turning to virtue ethics. A number of criticisms of VSD have been advanced in recent years that explicitly address VSD's reliance on a heuristic of values (cf. Le Dantec et al., 2009; Noemi MandersHuits, 2011). We will expand upon and go beyond these criticisms in order to motivate a 
turn whereby we take the structural characteristics of VSD and ground them in virtue ethics. From Vallor (2016) we adopt a heuristic of the virtues that is particularly attuned to the contemporary, technologically mediated human condition, and from MacIntyre (2007) we adopt a theory of technical practice. In VPD, the notion of design fulfils a different function than it does in VSD. That is, while VSD takes the design of artefacts and systems as the focus of intervention, VPD focuses at the technical practices in which these artefacts and systems are involved. This will also lead us to claim that "design" extends beyond technical choices and includes distinct considerations such as the education and training of practitioners and (legal) regulation of technical practices.

The paper is structured as follows. First, we will briefly introduce VSD and construct a criticism of its approach, both drawing from existing literature and developing some original critical points. Second, we will explain our move towards virtue ethics and provide an outline of this approach, focusing on the work of Vallor (2016) and MacIntyre (2007). Third, we will present VPD similar to VSD as consisting of three elements: (1) investigating narratives, (2) reflecting on the practices captured by these narratives using a heuristic of virtues and (3) prescribing aspects of relevant practices to enhance the extent to which they cultivate the virtues. We will illustrate the use of our method by focusing on a particular technology and technical practice, namely the operation of military drones.

\section{A Critique of Value Sensitive Design}

Different versions of VSD, varying for instance in the lists of values used, have been applied to particular technologies. However, certain central characteristics that are common to all versions of VSD can be identified. First, VSD proposes a tripartite methodology that can be applied iteratively during the design process of a technology. This methodology consists of conceptual, empirical and technical investigations (Friedman et al., 2006, p. 72). Second, all versions of VSD offer a certain heuristic - a certain list of values - that is meant to inform the process. With 'heuristic', we refer to what Sunstein frames a "moral heuristic" (Sunstein, 2003, p. 532), which is a conceptual structure that elicits moral intuitions, which are practically recognisable. The great merit of a heuristic in applied ethics lies in its capacity to incite practical associations in everyday settings, such as a project setting focusing on technology design, and thereby indicate what is to be 
considered morally significant. A list containing values such as 'privacy' or 'well-being' functions as a heuristic because it is used as a practical rule of thumb, as a collection of concepts that incite practical associations and thereby indicate what ought to be taken into account in a particular VSD investigation. Often, this heuristic is based on authoritative sources such as the Belmont report (cf. Friedman et al., 2006, p. 74) or the four ethical principles coming from principlism in bioethics (cf. Timmermans et al., 2011), but in general these heuristics of values are considered "incomplete" (Yetim, 2011, p. 5), which means that VSD admits of an inexhaustible plurality of values that can be considered. Third, VSD approaches implicitly or explicitly acknowledge that technologies are nonneutral and that values can be somehow "embedded" or "integrated" in technology design (Timmermans et al., 2011, p. 279). An account that is sometimes presented to confirm this latter point is Winner's (1980) example ${ }^{1}$ of how the design of an artefact can embody political and racist values and biases. In what follows, we will present a brief criticism of VSD, considering its central characteristics.

To start, we should ask what the added value of VSD is, or perhaps more poignantly, what is new about it. Certainly, a long tradition of normative ethics (utilitarianism, deontology, virtue ethics) could have provided designers with a considerable array of resources to reflect on their designs and ask whether these bring about desirable or undesirable consequences, an unwavering respect for persons, or whether these reflect or allow for the cultivation of certain virtues. We do not deny that in fact there is something particularly new about VSD, but we contest whether the contribution is to ethical theory. We argue that what VSD brings to ethics is to do with its application, its structural sensitivity to concrete design practices, rather than its focus on ethical values. 'Applying' for instance a utilitarian reflection to a design process is not straightforward, and what VSD primarily adds to the debate is the understanding that applied ethics should be responsive to the process to which it is applied. Thus, VSD contributes a component to applied ethics that renders it more responsive and relevant when being applied to concrete design processes than classical approaches in normative ethics. It tells us when ethical concerns play a role, who should be dealing with these concerns, and what steps should be taken to successfully incorporate them in the design process, which is very useful.

\footnotetext{
${ }^{1}$ See for instance: (Albrechtslund, 2007; Wilt et al., 2015)
} 
However, beyond this novel, application-related aspect of VSD it is not clear why the approach has adopted a pluralist heuristic of values as its basis in ethics, and it is especially this point that we will criticise. We develop our critique by advancing two critical claims: (1) that the notion of 'value' as operationalized by VSD runs the risk of either dealing with mere preferences or constituting an arbitrary heuristic, and (2) that the exclusive focus on values embedded in design of artefacts and systems leads to a narrow understanding of the potential impacts of technologies.

Ad. 1) It should be noted that VSD has initially developed a very broad and descriptive notion of value, being "what a person or group of people consider important in life" (Friedman et al., 2006, p. 70). Thus defined, 'values' do not seem particularly different from 'needs' or 'preferences', such as for instance invoked in "participatory design" (PD) 2 . Indeed, in some applications of VSD to investigate particular technology designs, values are initially considered as the equivalent of mere preferences, e.g. when 'affordable housing', 'minimal commute time' and 'environmental justice' are all taken as stakeholder values from people who run an urban planning simulation project (Borning et al. 2004, p. 69). Borning et al. (2004) then transpose these stakeholder values into 'moral values', which are stated as 'fairness', 'accountability', and 'democracy'. In making this step from stakeholder values to moral values, VSD seems to recognise the need to move from mere preferences to 'moral' values, but the question this raises is: how does this transposition happen? In a number of applications of VSD to a particular technology design a definite heuristic of 'moral values' is provided to avoid a reference to mere stakeholder preferences (cf. Cummings, 2006; Timmermans et al., 2011). The lists of values used vary substantially, but $a$ list is always used, such as the one comprised of 12 central values presented by Friedman and Kahn (Friedman and Kahn, Jr., 2003). At first sight, a pluralist heuristic of values as offered by VSD seems desirable, because it allows for rich analyses in which multiple values are discussed, respecting different ethical traditions and acknowledging the plurality of values across cultures. However, the concept of value in VSD is ambiguous and leads to a questionable notion of the 'embedding' of values in

\footnotetext{
${ }^{2}$ PD denotes a set of methods and tools that promote and structure the involvement of multiple direct and indirect stakeholders in the design process in order for their needs and preferences to be taken into account (Kensing and Greenbaum, 2013).
} 
design. Two approaches for arriving at a list of values can be conceived of: 1) departing from stakeholder preferences, and 2) offering a predefined list.

Manders-Huits provides an eloquent criticism of the first approach. She argues that VSD uses an "underdeveloped" notion of values, failing to distinguish between descriptive and normative values (Manders-Huits, 2011, p. 282). As such, VSD's imprecise characterisation of value conceals the problem that people's opinions of what is important in life often change (Manders-Huits, 2011, p. 279) and that outcomes of empirical investigations of people's preferences could be confused with ethical principles (ibid.). Because of this, VSD does not provide a grounding for the distinction between 'values' at large (i.e. what people find important in life) and 'moral values' (i.e. ethical principles supported by theory in normative ethics). Le Dantec et al. criticise the second approach, arguing that a pre-given heuristic of values might project values on an empirical case instead of eliciting the important moral values from it (Le Dantec et al. 2009, p. 1141). They argue that a heuristic implies a classification of values that are to be taken into account vis-à-vis those that are not, by which VSD runs into the danger of "cultivating a dogmatic response with respect to which values are worthy of consideration and disengaging from a commitment to understanding the nuanced manifestation of a plurality of values" (Le Dantec et al., 2009, p. 1142). The moral values to be taken into account are arrived at through classification and not through considering the context of the design.

What the abovementioned criticisms of VSD show is that the approach either departs from an investigation of stakeholder preferences, which leads to an underdeveloped notion of value as a mere preference, or from a fixed list of values that leads to an arbitrary and potentially dogmatic heuristic. We argue that this is largely the case because VSD does not engage with theories in normative ethics. Such theories are responsive to what people find valuable in life, but at the same time ground judgment concerning value (e.g. on what ought to be done, or what ought to be considered valuable) on a normative theory. For instance, hedonist utilitarianism might support 'privacy' as something that people find important in life, and simultaneously provide an account concerning why privacy ought to be valued (e.g. because of the pleasure one derives from non-interference in intimate situations). 
Ad. 2) The second part of our critique concerns the narrow focus of VSD on intervention into the design of artefacts or systems, which leads to a limited understanding of the ethical impacts of technologies. Central to VSD is the notion of values being embedded or incorporated in technology design. As mentioned before, this could for instance be understood by considering Winner's well-known example of the bridges built by Moses in Long Island, New York. Winner argues that these bridges were "deliberately designed to achieve a particular social effect" (Winner, 1980, p. 125), namely to prevent buses with predominantly poor and black passengers from reaching the beaches. $\mathrm{He}$ therefore considered the design of these bridges to be 'inherently political'. To be sure, the technological determinism in Winner's account (as well as its historical accuracy ${ }^{3}$ ) has been questioned in the wake of the so-called "empirical turn" (Achterhuis, 2001) in philosophy and ethics of technology. Nevertheless, what Joerges designates as the "designversion" (Joerges, 1999, p. 412) of the relation between technology design and social order seems to have remained closely related to the VSD methodology. Central to this designversion, as Joerges explains, is the notion of control (Joerges, 1999, p. 427): the idea that through intervention in design one might control social outcomes.

This point can be illustrated by a case study of VSD in one of its founding texts (Friedman, Kahn Jr. and Borning, 2006). In discussing the application of VSD to the design of an urban simulation system, it is argued that the design of the system should not discriminate, should be accountable and should support democratic processes (Friedman et al., 2006, p. 82). To this end, different software architecture changes are proposed, for instance making the spatial scale of the urban simulation more fine-grained to be able to better model walking as a mode of urban transportation. Thus, though perhaps espousing an idea of values inherent in design more nuanced than Winner's, VSD shows a strong focus on the idea that through value-based interventions into technology design certain social outcomes can be achieved. In line with Joerges, we challenge this focus on control through choices in technology design. That is, we do not want to deny that design choices are important (i.e. the 'politics' inherent in design), but rather that additionally the 'politics of artefacts' is to be taken into account. This means that technology design only leads us

\footnotetext{
${ }^{3}$ Joerges challenged Winner's account, questioning his depiction of Moses' intentions in designing the low bridges in New York (Joerges, 1999).
} 
to a partial, narrow understanding of the ethical impacts of technologies and that in order to broaden up this understanding we would have to take aspects into account that are not related to design such as education, training, teambuilding, laws, codes of conduct, ethical oaths, and so forth. Hence, even though VSD purports that it takes values into account that extend beyond the workplace (Friedman et al., 2006, p. 85), its narrow focus on intervention into design leads to the disregard of factors of human development and regulation as crucial to a proper understanding of the ethics of technology. We argue that this narrow focus can best be understood in terms of VSD's emphasis on the design of artefacts and systems, thereby neglecting the technical practices in which these are involved. We believe that the inclusion of technical practices would lead to a better understanding of the ethical impacts involved. In the case of Moses' bridges, for instance, it would lead to considerations of regulations applying to the practice of architectural work, or to the empowering of minorities to participate in the practice of democratic decisionmaking to change a city's infrastructure plan.

\section{Turning to Virtue Ethics}

Considering the criticism we constructed, we develop VPD as an alternative to VSD in that it (1) offers a way to ground the heuristic of values in a normative theory (thereby turning to a heuristic of the virtues) and (2) broadens up VSD's narrow and exclusive focus on technology design by including technical practices in which artefacts and systems are involved.

In order to tackle the above critique of VSD two different ways forward can be envisioned. 1) The first way forward would be trying to 'save' VSD's reliance on a pluralist heuristic of values, which can be done by considering different strategies. Dantec et al. advocate a stronger focus on the empirical stage of the method, and the "value discovery" in this stage (Le Dantec et al., 2009, p. 1145). In other words, by asking stakeholders about their value preferences, the local values that are important in a particular context are disclosed and the potential dogmatism of pre-given lists of values is avoided. However, this returns us to the problem of distinguishing between mere preferences and moral values, because no other criteria for local values are provided apart from them being expressed by stakeholders. Manders-Huits proposes another way forward through the notion of "value- 
conscious design" (Manders-Huits \& Zimmer, 2009), and through solving its challenges of justifying value-frameworks that are used, defining and justifying the roles of advocates of these frameworks and providing for strategies to solve value conflicts. However, no concrete ways of solving these challenges are provided and arguably one would need to return to normative ethics to properly address them. Van de Poel offers another way to ground VSD's value heuristic, namely by offering a "value hierarchy” (Van de Poel, 2014), consisting of moral values, norms and specific design requirements. In this hierarchy, a moral value such as democracy could lead to the norm ' 1 man 1 vote' and the related design requirement 'one voting pass for each voter'. Moral values are considered as values for the sake of which norms are implemented and design requirements are followed. Nevertheless, the problem with Van de Poel's value hierarchy is that it does not account for reasons why norms are followed. For instance, in the abovementioned example, his framework does not explain why democracy is a value of moral importance that ought to be followed. The only reason for it to be posited appears to be that stakeholders prefer democracy as a value.

2) The second, more promising way forward, is to ground the heuristic used in VSD by means of a normative theory in ethics. Two notable examples can be given in this regard. Yetim integrates VSD with Habermas' discourse ethics, which allows him to justify the distinction between "moral norms" and "cultural values" (Yetim, 2011, p. 142). However, even though this approach takes well-conceived steps in expanding the design community, it retains a strong focus on the technology design of artefacts and systems. Van Wynsberghe (2013) seems to have gone to the furthest extent so far in providing grounding for VSD's value heuristic, by introducing care ethics as an axiological theory. In her framework, care is conceived as the grounding principle from which other values are derived based on their role in caring for others (van Wynsberghe, 2013, p. 415). Moreover, she does not merely focus on technology design but explicitly on care practice as leading to the values that are of importance (attentiveness, responsibility, competence, responsiveness) and to elucidate the multitude of practices in which the technology in question (care robots) are involved. However, we still see some shortcomings in this approach. Most importantly, the concept of 'practice' remains very thin and is conceptualised as involving both thought and action aiming at a certain end. It remains unclear in her account how practices are made intelligible, and what distinguishes them for 
instance from basic, thoughtful actions such as moving a piece on the chessboard. It seems that almost all human activities, including for instance 'bathing' and 'lifting' in the interaction between humans and care robots, can be seen as practices.

In developing our alternative approach, we stay close to the strategy of van Wynsberghe (2013) but we take virtue ethics as our starting point instead of care ethics. As we will show below, virtue ethics is promising in some crucial respects in dealing with our critique. First, similar to the 'values' in VSD, the virtues originate from a practical, everyday heuristic, what Aristotle referred to as belonging to "common beliefs" (NE, 7.1, $1145 \mathrm{~b} 4-8$, trans. Irwin). For instance, the concept of 'courage', which denotes a virtue, is used in everyday life to incite a practical association with a state of character that is referred to as being in accordance with virtue. At the same time, the virtues relate to and are supported by a certain philosophical anthropology, such as the one developed by Aristotle. This addresses the first concern in our critique of VSD because (a) on the one hand the heuristic of the virtues is not arbitrary because it is supported by a normative theory, and (b) on the other hand the heuristic remains responsive to stakeholder engagement because the relevant virtues can be derived from the expressions of standards of excellence and life plans that relate to a certain technical practice. Second, virtue ethics has practice as its aim, meaning for VPD that its point of intervention is always a technical practice in which humans and technologies interact. This focus can lead to the prescription of for instance laws or educational activities, next to prescriptions concerning design requirements. Moreover, VPD makes explicit how practices are made intelligible, namely through narrative, and what aspects of practices are important to consider, namely standards of excellence and life plans. It thereby offers a comprehensive, delineated concept of practice, which does not include all human actions (i.e. excluding actions to which no standards of excellence or life plans can be ascribed). This addresses our second concern regarding the narrow focus of VSD on design because (a) the scope of concern and intervention in VPD is significantly broadened, focusing on technical practices and (b) it includes prescriptive interventions that go beyond technology design and include considerations of human development and regulation.

'Virtue ethics' refers to one of the most ancient traditions in ethics that in the Western world predominantly relies on the writings of Aristotle (references). Central to his 
tradition is the idea that human beings tend to an ultimate good, called eudaimonia. The virtues are a person's dispositions to act, or states of character that incline her to act in accordance with this ultimate good. Virtues and action are intimately connected, because it is through action in accordance with virtue that virtues are cultivated. In relation to applied ethics of R\&I, virtue ethics has recently been put back on the agenda by scholars such as Ess (2009) and Coeckelbergh (2012). Vallor (2016) has taken the approach to its furthest extent by providing a comprehensive account of virtue ethics of technology. In her work, she provides an account of the conditions under which the virtues can be cultivated in the modern age, a reasoned heuristic of 'technomoral' virtues that are particularly relevant in our dealings with modern technologies, and an application of her framework to particular technologies such as human enhancement technologies. To construct her virtue ethics framework, she draws from Aristotelian, Confucian and Buddhist accounts of the virtues. What Vallor does not do, however, is provide a practical method similar to VSD that would allow virtue ethics to be applied to design processes in accordance with the iterative structure of those processes.

We argue that virtue ethics could be used as the basis for a method for practising ethics in R\&I that adopts merits of VSD concerning the responsiveness to the design process but avoids the difficulty of having value as its central concept and instead puts virtue at the centre stage. The first important aspect that would be different in such an approach is that instead of the design of a thing (i.e. a technology, an artefact), it is the 'design' or shaping of a practice that is at stake in VPD. The reason for this is that a technical object itself does not cultivate the virtues, but only practices in which such an object is involved. We would therefore need an account of practice, which can be attained by considering MacIntyre's account of virtue ethics. Virtue, for MacIntyre, is "an acquired human quality the possession and exercise of which tends to enable us to achieve those goods which are internal to practices and the lack of which effectively prevents us from achieving any such goods" (MacIntyre, 2007, p. 191). A practice is a socially established activity through which goods internal to that activity are realized (MacIntyre, 2007, p. 187). For goods to be 'internal' to a practice means that the so-called standards of excellence according to which a practice can be evaluated are exhausted by the practice itself. For instance, 'playing the piano well' is determined by standards of excellence that are 
exhausted by the performance of a pianist playing the piano. However, 'making a good trade' on the stock market is determined by a standard such as making a profit, which is external to the activity of trading itself.

But how do we understand practices according to their standards of excellence? MacIntyre answers this question by referring to narrative (MacIntyre, 2007, p. 206), stating that practitioners explain their practices (e.g. 'he plays the piano well, because...') in the narrative mode; according to a story line. As such, practices belong to practical narratives called 'life plans', for instance of being a piano player, a student, or a computer scientist. These life plans, in turn, are embedded within a 'moral tradition', which provides a particular conception of the good life to practitioners. Thus, the standards of excellence of 'designing a computer program' could be determined by the life plan of being a computer scientist (i.e. a narrative, recounting what it means to be a good computer scientist), which in turn relates to a conception of the good life in a particular moral community. Because traditions differ, the standards of excellence might differ between moral communities, implying that 'being a good computer scientist' might mean different things in for instance a Buddhist or in a Christian moral community. What we can derive from MacIntyre's theory of practice is that in order to know whether and how a practice cultivates the virtues, we need to inquire into narratives that both reveal a particular conception of the good life and the standards of excellence that govern the practice in question. This insight, we argue, can lead to a restructuring of VSD so that is becomes responsive to the notion of virtue.

\section{Virtuous Practice Design: A Tripartite Method}

Like VSD, VPD uses a heuristic (i.e. a list of the virtues), but in contrast to VSD it uses a heuristic that systematically relates to its underlying theory of virtue ethics. That is, by taking Vallor's (2016) heuristic of the virtues, we do not simply introduce an arbitrary list, but a list of virtues that are justified by referring to the normative theory that grounds them. Unlike 'values' in VSD, the virtues can therefore be criticised by reference to the arguments that underlie the normative theory from which they are derived and do not result from the arbitrary judgment of the person who happens to apply the method to a particular case. Using both MacIntyre's notion of practice and Vallor's heuristic of the virtues, we 
therefore propose the tripartite method developed below. We illustrate how this method responds to a concrete technical practice using the case of a pilot operating military drones. ${ }^{4}$

\section{(1) Investigation of narratives}

First, rather than putting central emphasis on a particular technological artefact or system, emphasis is put on the notion of practice, considered as the type of activity that is mediated by a given technology and which can support or obstruct the cultivation of the virtues. By putting practice at the centre of the investigation, we follow the recommendation of Le Dantec's et al., prioritising the empirical investigations of the technological practice in question (Le Dantec, Poole and Wyche, 2009). We should emphasise that we thereby roughly follow Aristotle's (1999) characterisation of method in ethics: which states that one should start from "common beliefs", critically reflect on these, and eventually turn back to the common beliefs by either confirming or revising them (NE, 7.1, 1145b4-8, trans. Irwin). Linking this with MacIntyre's notion of practice, we argue that we first need to aim at understanding relevant practices by gathering and investigating narratives that recount related standards of excellence and life plans. These narratives can be gathered from interactions with relevant stakeholders, which can be people making, using or governing a certain technology. In this light, we consider the example of a military drone. Multiple distinct practices can be identified in relation to this particular technology: the practices of designing, producing, and marketing the technology, of operating and maintaining the technology, and of regulating, monitoring, and protesting against the technology. Each of these practices will have its particular standards of excellence that link to particular life plans, and will point at a distinct type or group of stakeholder(s).

To illustrate the use of our method, we consider the technical practice of operating a military drone. The particular type of stakeholder that is of interest with regard to this practice is the military personnel working in ground bases to operate military drones from a distance, for instance working from a base in Nevada to operate a drone that is active in

\footnotetext{
${ }^{4}$ We should note the following: (1) that we do not intend to contribute to the extensive literature on just war theory and military drones (cf. Brunstetter \& Braun, 2011; Williams, 2015), but merely take this case as an illustrative example for our approach and (2) that the application of our method to the case is incomplete, because a technical artefact such as a military drone is involved in multiple practices, including those of the victims of drone attacks, of policy makers regulating the use of military drones, and so forth. With regards to this latter point, we should stress that a comprehensive appraisal of military drones in light of our approach ought to focus on a multitude of technical practices and will never be absolutely complete.
} 
Afghanistan. Gathering relevant narratives that would allow us to understand this particular practice would, similar to VSD, involve the use of social science methods such as focus groups or narrative interviews, aimed at eliciting the relevant narratives from stakeholders. We refer in this case to a third source containing a narrative interview, namely an interview with a drone pilot that was published in the German magazine Spiegel, which focused on the practice of operating a military drone in combat situations (Pitzke, 2010). The recounted narrative capturing the practice of operating a drone contains references both to standards of excellence and to life plans. We can illustrate this with the following four quotes from the interview:

[1] Pilots are pretty good at compartmentalizing [different aspects of life]. They teach you that early and often (Pitzke, 2010).

[2] You get more attached than you would think from being in Nevada. For instance, you're trying to protect those guys on the ground (Pitzke, 2010).

[3] The other guys are exposing themselves, and that to me is still quite an honorable thing to do. So I feel like I'm cheating them (Pitzke, 2010).

[4] Killing someone with an RPA is not different than with an F-15. It's easy to think that, to fall down that trap. We're well aware that if you push that button somebody can go away (Pitzke, 2010).

Standards of excellence that can be derived from these quotes that are part of the narrative concerning the practice of flying a military drone are (1) compartmentalizing different aspect of life, (2) engaging in combat to protect fellow soldiers and (3) taking responsibility for the decision to strike. These standards of excellence relate to a life plan, notably that of being a military pilot, which is embedded in a moral community that contains certain standards for what it means to be a military pilot. A novel practice, such as operating a military drone, can conflict with the conception of the life plan in a moral community, as is characterized by the third quote. That is, the practice of operating military drones in a way obstructs a standard of excellence of "being a pilot", which is that one should share in the vulnerability of fellow soldiers while engaging in combat. By deriving standards of excellence and life plans from narratives concerning a particular practice, we gain a better 
understanding of the practice; one that can inform our ethical reflections that make use of the heuristic of the virtues.

\section{(2) Reflection based on the virtues}

The second step of our method entails moving from the descriptive and interpretative account of a practice to a normative reflection of that practice, which is based on a heuristic of the virtues that is developed by Vallor (2016). Without spelling out the entire heuristic, we will discuss the following virtues in particular:

- Perspective, related to the need for a better understanding of the impacts of emerging technologies.

- Empathy, related to the need to deal with the influence of digital culture on our interpersonal relations.

- Justice, related to the need to address the increasing unjust distribution of resources and power through technological communication channels.

Let us return to the example of operating a military drone. The standard of excellence expressed in the first quote allows for a reflection on the practice by considering the virtue of perspective. A standard of excellence for a military pilot is told to be to separate different aspects of life, to not let troubles during combat affect other aspects of political, family, or community life. The aim of such a standard is somewhat aligned with the virtue of perspective, because it is meant to deal with what Vallor designates as the "sense of scale" that is involved in military operations (Vallor, 2016, p. 149). However, it obstructs the cultivation of perspective because perspective should, as opposed to "compartmentalization", incline practitioners to "attend to, discern, and understand moral phenomena as meaningful parts of a moral whole" (ibid.). Learning to strictly separate different aspects of life as an aspect of the practice of operating a military drone can therefore be criticised by considering the virtue of perspective.

We can reflect upon the second and third quotes by considering the virtue of empathy. On the one hand, the operation of military drones seems to bring combatants closer to their fellow soldiers on the ground because they are in constant contact with them. On the other hand, however, empathy, which Vallor relates to the Aristotelian virtue of friendship (Vallor, 2016, p. 134), requires reciprocity, which means that those who are 
empathic towards one-another need to have an equal share in their joint practice. As the drone pilot indicates, he is not able to establish this equality in the practice of operating the drone because he is not exposed to danger in the same way as his fellow combatants on the ground. Even though one would expect this lack of equality to be an issue of concern for the opposing forces, it is somewhat remarkable to see it expressed as a concern for those who have been placed out of harm's way. Thus, proportionality in warfare is even an issue for those benefiting from a disproportionate situation, because it obstructs the virtue of empathy, which requires reciprocity in order for the practice of operating a military drone to be worthy of honour and recognition.

The fourth quote invokes a reflection on the practice of drone strikes by considering the virtue of justice. The pilot invokes a sense of responsibility with regard to the decision to 'press a button' that will result in the killing of people that are supposed to be enemy combatants. This responsibility extends to the unknown other, whose life can be taken by means of a decision in the practice of operating a military drone. Vallor in part characterises the virtue of being just as having a "concern for how emerging technologies impact the basic rights, dignity, or welfare of individuals and groups" (Vallor, 2016, p. 128). The responsibility that comes with the decision to kill an unknown individual therefor has to be accompanied by a consideration for the dignity of that individual as a human being. In a certain interpretation, this could lead one to altogether condemn the use of military drones in situations of war. According to another interpretation that would take the idea of a just war into account, it would at the very minimum call for a practitioner to be inclined to reflect on the justifiable nature of a military conflict and of each particular decision taken in this conflict.

\section{(3) Prescriptions for technical practices}

The third step in our method mirrors the technical investigations in VSD but is considerably broader because it looks at a practice in its entirety and not only at the technical design of a particular technology. As such, this stage is concerned with prescribing certain aspects of the technical practice, which could relate to aspects of the design of the technology used in the practice but also to a variety of other aspects, such as training, education, and regulation of the practice. We can categorise these different types of prescriptions according to (1) human development, (2) design, and (3) regulation. We will consider 
prescriptions related to each of the reflections on the practice of operating a military drone, in accordance with the virtues that we invoked.

The first standard of excellence that we reflected upon was learning to compartmentalise different aspects of life, which we argued obstructed the virtue of perspective. The emphasis on 'learning' indicates that what is at stake is the development of the practitioner, through education and training. What could be done in order to aim at a sense of scale (i.e. the scale of warfare vis-à-vis the scale of everyday life), while at the same time attending to the interconnectedness between these different aspects of life with regard to a moral whole (i.e. an overall conception of the good life), would be to educate military pilots to have a practical understanding of political philosophy. This would incline a pilot to interpret decisions he would have to take in the moment (e.g. initiating or withdrawing from a strike in order to potentially save fellow combatants) in relation to an understanding of the good life in a political community. Through cultivating a sense of perspective through education, a pilot might consider withdrawing from striking and to conscientiously object in case the reason for engaging in a mission would conflict with his notion of the good life in a political community.

The second standard of excellence, of being equally exposed to danger in a context of combat, could lead to a reconsideration of the design of the technological infrastructure supporting drone strikes. Instead of moving the operations far away from the actual zone of combat, innovations of design of the support infrastructure could make it possible to move them closer to the combat zone in a responsible way. Taking this issue into account, designers could for instance focus on the creation of mobile control centres that would operate in vehicles deployed within the zones of combat. This could raise the risks of drone pilots to be harmed. Yet considered in relation to the virtue of empathy this would be integral to their achieving a sense of shared vulnerability. As such, design can play a crucial role in increasing a technology's capacity to promote practices that cultivate the virtues.

The third standard of excellence, of taking responsibility for the decision of killing another human being through the pressing of a button, which we related to the virtue of justice, could lead to prescriptions of certain types of regulations. We can discern a relation between the virtue of justice invoked here and the virtue of perspective invoked earlier. Given that a pilot of a military drone is inclined to act in accordance with the virtue of 
perspective, they will simultaneously be inclined to treat their opponents justly, considering their basic human dignity. A certain regulatory framework, in addition to the proper type of education mentioned earlier, could promote pilots to engage in the practice of operating a military drone justly. For instance, a regulatory framework could accommodate conscientious objection to a certain aspect of the operation, or to the practice of drone operation in its entirety. In practical terms, this means that pilots of military drones should have the legal option to object to certain orders, provided that they have to take responsibility for such objections and justify them in court. For such a practice of justification, particular standards of excellence could be established (e.g. a pilot could be expected to provide reasons that are not arbitrary but related to a conception of justice that can be supported by circumstantial evidence - such as the absence of sufficiently clear information to distinguish civilian from military targets).

We acknowledge that the above presentation of VPD is only an initial attempt to formulate a method based on virtue ethics that is responsive to R\&I contexts. Future inquiries will be indispensable and should focus on both the practicality of the method and on the strengths and weaknesses of the virtue ethics approach. To provide an example of a future inquiry, we mention some of the problems in MacIntyre's model of practice. First, MacIntyre presents a potentially problematic relation between a tradition and standards of excellence, which suggests that standards of excellence are derived from a tradition belonging to a moral community and that innovation from the bottom up is not adequately covered. That is, if traditions provide practitioners with standards of excellence, how can these practitioners challenge these standards if they perceive of them as being detrimental to their particular conception of the good life? Second, MacIntyre's narrative theory focuses on a life's narrative as a series of recounted experiences, such as an autobiography, and leaves little room for the impact of fictional narratives. Arguably, though, fictional narratives for instance in literature such as Orwell's 1984 can have a profound impact on the way practitioners understand the practices they engage in (e.g. securing and ICT environment). To tackle these issues in MacIntyre's theory of practice, one could for instance consider Ricoeur's (1992) theory of practice and related narrative theory ${ }^{5}$ that

\footnotetext{
${ }^{5}$ For approaches in applied ethics that depart from Ricoeur's philosophy, see e.g. Romele (2017) and Reijers \& Coeckelbergh (2016).
} 
both address the tension between innovation and tradition and incorporate historical and fictional narrative.

\section{Conclusion}

In this paper, we have shown how an approach that takes virtue instead of value as the central notion for aiming at design that is sensitive to ethical concerns can be fruitful both in theory and in practice. Following up on a critique of VSD, we have argued how virtue ethics offers a heuristic for moral reasoning that is grounded in a normative theory and that it is promising in aiming at technical practice as the point of intervention, which broadens the scope of moral concern. Basing our approach on the work by Vallor and MacIntyre, we have showed how narrative accounts of a technical practice can lead to an understanding of how it relates to certain standards of excellence and life plans, how these can be evaluated by means of the virtues, and how this evaluation can lead to forms of prescription in terms of human development, design and regulation. By focusing on a technical practice of operating military drones we have given an example of the application of the approach.

\section{References}

Achterhuis, H. (2001) 'American Philosophy of Technology: The Empirical Turn'. Indiana: Indiana University Press.

Albrechtslund, A. (2007) 'Ethics and technology design', Ethics and Information Technology, 9(1), pp. 63-72. doi: 10.1007/s10676-006-9129-8.

Aristotle (1999) Nicomachean Ethics. Edited by T. Irwin. Indianapolis: Hackett Publishing Company.

Borning, A., Friedman, B. and Kahn, P. H. (2004) 'Designing for Human Values in an Urban Simulation System : Value Sensitive Design and Participatory Design', in PDC-04 Proceedings of the Participatory Design Conference, Vol 2, Toronto, Canada. Palo Alto, pp. 68-71.

Coeckelbergh, M. (2012) 'Care Robots, Virtual Virtue and the Best Possible Life', in Brey, P., Briggle, A., and Spence, E. (eds) The Good Life in a Technological Age. New York: Routledge.

Cummings, M. L. (2006) 'Integrating ethics in design through the value-sensitive design 
approach', Science and Engineering Ethics, 12(4), pp. 701-715. doi: 10.1007/s11948-0060065-0.

Le Dantec, C. a., Poole, E. S. E. S. and Wyche, S. P. S. P. (2009) 'Values as lived experience: Evolving value sensitive design in support of value discovery', in Proceedings of the 27th international conference on Human factors in computing systems (CHI '09), pp. 1141-1150. doi: 10.1145/1518701.1518875.

Dignum, M., Correljé, A., Cuppen, E., Pesch, U. and Taebi, B. (2016) 'Contested Technologies and Design for Values: The Case of Shale Gas', Science and Engineering Ethics, 22(4), pp. 1171-1191. doi: 10.1007/s11948-015-9685-6.

Ess, C. (2009) Digital Media Ethics. Camebridge: Polity Press.

Friedman, B. (1996) 'Value-sensitive design', Interactions, 3(6), pp. 16-23. doi: $10.1145 / 242485.242493$.

Friedman, B. and Kahn, Jr., P. H. (2003) 'Human Values, Ethics, and Design', The HumanComputer Interaction Handbook, pp. 1177-1209.

Friedman, B., Kahn Jr., P. H. and Borning, A. (2006) 'Value Sensitive Design and Information Systems', in Himma, K. E. and Tavani, H. T. (eds) Human-Computer Interaction and Management Information Systems: Foundations. John Wiley \& Sons, Inc., pp. 1-27. doi: 10.1145/242485.242493.

Friedman, B. and Kahn, P. (2002) 'Value sensitive design: Theory and methods', University of Washington Technical, (December), pp. 1-8. doi: 10.1016/j.neuropharm.2007.08.009.

Joerges, B. (1999) ‘Do Politics Have Artefacts?’, Social Studies of Science, 23(1), pp. 411431.

Kensing, F. and Greenbaum, J. (2013) 'Heritage: Having a Say', in Simonsen, J. and Robertson, T. (eds) Routledge International Handbook of Participatory Design. New York: Routledge.

MacIntyre, A. (2007) After Virtue: A study in moral theory. Third Edit. Notre Dame, Indiana: University of Notre Dame Press. doi: 10.1017/CBO9781107415324.004.

Manders-Huits, N. (2011) 'What Values in Design? The Challenge of Incorporating Moral Values into Design', Science and Engineering Ethics, 17(2), pp. 271-287. doi: 10.1007/s11948-010-9198-2. 
Manders-Huits, N. and Zimmer, M. (2009) 'Values and Pragmatic Action: The Challenges of Introducing Ethical Intelligence in Technical Design Communities', International Review of Information Ethics, 10, pp. 37-44. Available at: http://fiz1.fhpotsdam.de/volltext/ijie/09123.pdf.

Pitzke, M. (2010) 'It Is Not a Video Game', Spiegel. Available at: http://www.spiegel.de/international/world/interview-with-a-drone-pilot-it-is-not-a-videogame-a-682842.html (Accessed: 24 May 2018).

Poel, I. Van de (2014) 'Translating Values into Design Requirements', in Michelfelder, D. P. (ed.) Philosophy and Engineering: Reflections on Practice, Principles and Process. Dordrecht: Springer, pp. 253-266. doi: 10.1007/978-94-007-7762-0.

Reijers, W. and Coeckelbergh, M. (2016) 'The Blockchain as a Narrative Technology: Investigating the Social Ontology and Normative Configurations of Cryptocurrencies', Philosophy \& Technology. Philosophy \& Technology, 7. doi: 10.1007/s13347-016-0239$\mathrm{X}$.

Reijers, W., Wright, D., Brey, P., Weber, K., Rodrigues, R., O’Sullivan, D. and Gordijn, B. (2017) 'Methods for Practising Ethics in Research and Innovation: A Literature Review, Critical Analysis and Recommendations', Science and Engineering Ethics. Springer Netherlands, pp. 1-45. doi: 10.1007/s11948-017-9961-8.

Ricoeur, P. (1992) Oneself as Another. Edited by K. Blamey. Chicago: University of Chicago Press.

Romele, A. (2017) 'Imaginative Machines', Techné: Research in Philosophy and Technology, 22(1), pp. 98-125. doi: 10.5840/techne201791369.

Sunstein, C. R. (2003) 'Moral Heuristics', Behavioral and Brain Sciences, 28(4), pp. 531541.

Timmermans, J., Zhao, Y. and van den Hoven, J. (2011) 'Ethics and Nanopharmacy: Value Sensitive Design of New Drugs', NanoEthics, 5(3), pp. 269-283. doi: 10.1007/s11569011-0135-x.

Vallor, S. (2016) Technology and the Virtues: A Philosophical Guide to a Future Worth Wanting. Oxford: Oxford University Press.

Wilt, G. J. van der, Reuzel, R. and Grin, J. (2015) 'Design for Values in Healthcare Technology', in van den Hoven, J., Vermaas, P. E., and van de Poel, I. (eds) Handbook of 
Ethics, Values, and Technological Design: Sources, Theory, Values and Application Domains, pp. 1-871. doi: 10.1007/978-94-007-6970-0.

Winner, L. (1980) 'Do artifacts have politics?', Daedalus, 109(1), pp. 121-136. doi: $10.2307 / 20024652$.

Van Wynsberghe, A. (2013) 'Designing Robots for Care: Care Centered Value-Sensitive Design', Science and engineering ethics, 19(2), pp. 407-33. doi: 10.1007/s11948-0119343-6.

Yetim, F. (2011) 'Bringing discourse ethics to Value Sensitive Design: Pathways toward a deliberative future', AIS Transactions on Human-Computer Interaction, 3(2), pp. 133-155. doi: 10.5121/ijfcst.2014.4403. 